\title{
Socio-Cultural Context of Innovative Development
}

\author{
Hanna Pylypenko \\ Doctor of Economic Sciences, Professor, Dnipro University of Technology \\ (Dnipro, Ukraine) \\ E-mail: annapylyp@ukr.net \\ https://orcid.org/0000-0003-2091-4320 \\ Nataliya Lytvynenko \\ Doctor of Economic Sciences, Associate Professor, Dnipro University of Technology \\ (Dnipro, Ukraine) \\ E-mail: natalyt33@ukr.net \\ https://orcid.org/0000-0003-3797-8398
}

\section{Tamara Barna}

\author{
Doctor of Philosophy, Dnipro University of Technology \\ (Dnipro, Ukraine) \\ E-mail:nv.ngu@ukr.net \\ https://orcid.org/0000-0002-3152-8778
}

The article presents the results of empirical studies of correlation of culture and innovations. Sociocultural factors of innovative development have been revealed. The present research has established the dual nature of innovations that finds itself in a symbiosis of an innovation and a creativity product. This fact allows us to view this phenomenon as a result of interaction of the economic and sociocultural spheres of society's life activity: an innovative impulse arises from a person's desire to gain an economic benefit, on the one hand, and from a desire to reach the originality that is specified by traditions of a certain culture, on the other hand. Consequently, innovative activity depends directly on socio-cultural values that determine human dispositions, habits and motivations.

Sh. Schwartz's calculation of value indices allowed us to reveal the human value priorities in twentyone countries of Europe in terms of their influence on person's innovative dispositions, using the data body of International comparison project "European Social Survey" (2012-2016). It was shown that in the countries with dominant "Openness to Changes" values, inventiveness and innovativeness are more pronounced if compared to the countries where "Conservatism" values prevail. There has been demonstrated the special importance for innovative development of "Self-Transcendence" values that facilitate the formation of an environment favourable for implementing the institutional innovations. The research has proved that average Ukrainians have no value disposition to innovations. This fact creates a cultural barrier on the way of Ukraine's innovative development and requires governmental impact on these processes.

\footnotetext{
(C) Pylypenko, Hanna, 2019

(C) Lytvynenko, Nataliya, 2019

(C) Barna, Tamara, 2019
} 
The authors have taken into account the global modern development tendencies that manifest themselves in strengthening the countries' interdependency, particularly, in more rapid cultural convergence, gradual unification of values, with cultural diversity preserved. With this in mind, to intensify the innovative activity in Ukraine, the authors suggested a strategy of Ukraine's deeper integration into the world science and technology space as an equal partner as well as searching for its niche in a constantly developing world segment of creative and innovative activity, with cultural diversity being a powerful source of development.

Keywords: innovations, innovative activity, cross-cultural analysis of innovations, person's innovative dispositions, socio-cultural innovation factors, Schwartz's value orientations for Ukraine, cultural barriers of innovative development

Received: February 15, 2019; accepted: May 2, 2019

Philosophy and Cosmology, Volume 23, 2019: 98-111.

https://doi.org/10.29202/phil-cosm/23/9

\section{Introduction}

Investigating the social and economic space, the modern economic science has always given priority to its technical and technological components. It has also considered innovations to be a determinant factor of increasing the economic growth of each specific country and providing its competitive positions on the world markets. However, the theoretical and practical recognition of innovation importance, the formation of a relevant legislative base, the development and implementation of government innovation programs have not created powerful factors of Ukraine's innovative development. In terms of the innovation statistics in Ukraine, the State Statistics Committee proves the fact that only 16,2 \% of enterprises performed innovative activity, if compared to $60-70 \%$ of enterprises in developed countries. Moreover, the specific weight of the total research and development expenditures within the GDP of Ukraine was $0,47 \%$, whereas in 28 EU countries the average figure was about 2,06\% [Research and Development, 2018]. There arises a logical question: why does not the Ukrainian economy become innovative, despite all the government efforts?

Referring to the scientific sources on this problem allows us to understand that the most widely spread approach in studying innovative development is considering the innovations as a phenomenon of mostly technical and economic nature. What is emphasised is the limited resource base that makes the mankind search for new sources of raw materials, energy and forms of organisational relationships to enhance the economy's production capabilities. As such, enhancement is possible due to the human economic activity, the economic science focuses on revealing the determinants (motives) of human innovative activity. The most important of these determinants is a desire to maximise the economic benefit that manifests itself as an innovation quasi-rent [Yakovets, 2003]. This quasi-rent is understood as a differentiated scientific and technical income (superprofit) received by an entrepreneur who was the first to master a more efficient and principally new technical device, technologies or methods of business organisation.

Apparently, such a narrow economic approach cannot reflect the whole spectrum of motivation mechanisms of innovative activity, as it greatly narrows the system of existing parameters of economic subjects' behaviour. In the real world of economics, people are not motivated by egoism only, but they have many other operative motives - altruism, habit, custom, sense of law, sense of duty, etc. Consideration of these factors, which are far from 
economics at first sight, allows us to reveal non-economic variables that stipulate human behaviour and are thus potentially capable of restraining or speeding up the innovative development of the economic system.

\section{Methodology of investigating the innovative development factors}

To understand a man in his entire motives, stimuli and interests, he should be viewed as a subject of an integral polysystemic society. Formulation of the problem within this context requires special research methods. In our opinion, this can be a structural and functional approach proposed by Emile Durkheim and Talcott Parsons, the founders of the functionalism school in sociology. The use of the structural and functional approach allows one to see that the contemporary society is a complex system of interdependent and interrelated spheres of economics, politics, law, cultures. They interact so closely that, when influencing one of them, it is impossible to change the functioning of the whole system. Therefore, viewing the innovations as an economic element only, we miss a whole spectrum of motivational mechanisms for innovative activity of economic subjects who take decisions on technological development perspectives.

These variables are introduced in the analysis by mental "plunging" of the autonomous technological system into a complex of interdependences and interrelations of the existing subsystems of a society that is viewed as an integral body [Pylypenko, 2012]. Gnoseologically, such a methodology approach allows us to reveal the aspects of innovative activity that are formed due to the fact that other society subsystems perform their integrative functions. With such understanding of society's functioning, one can find out that the human economic activity, including the innovative activity, is stipulated by the whole complex of economic, political, legal, cultural and other factors united with a concept of institutional environment.

In fact, an institutional environment is a factorised medium of a society's economic system, and is a total sum of formal and informal institutions. Being a system of behavioural norms and rules, each institution is based on socio-cultural values that were acquired and passed from one generation to another through culture. Therefore, culture is often viewed as a most important information aspect of society's life activity, which is manifested in behavioural patterns [Pylypenko, 2017]. In fact, culture helps to choose such a behavioural model that allows one to optimise the use of limited resources to provide for a maximum possible number of needs. This is directly related to innovations. However, understanding the main point of the cultural influence on the economics is not enough for it to be used in practice. To take account of the national specific features of innovative development, we need to have at least a few quantity indicators. According to Nadezhda Lebedeva, despite the fact that culture is a phenomenon that is difficult to perceive, but possible to feel, a phenomenon that is difficult to understand and even more difficult to measure and drive into formalised mathematical statistics and modelling, culture can be and should be measured [Lebedeva \& Tatarko, 2009].

This is done by the methods and instruments developed in the late $20^{\text {th }}$ century in terms of the cross-cultural analysis. Such scholars as Geert Hofstede, Ronald Inglehart, Harry Triandis, Fons Trompenaars, Shalom Schwartz and others suggested methodological approaches that allow one to empirically reveal and fix the influence of culture on various aspects of human economic activity.

In our research, we use the culture measuring approach developed by Shalom Schwartz, Professor of Psychology at the Hebrew University of Jerusalem. This approach is based on a hypothesis that all societies face certain basic problems in regulating human activity, and sociocultural values determine ways used by various societies to solve these problems. Sh. Schwartz 
focuses on value orientations, which are, in his opinion, external in relation to people and are manifested in specific stimuli and expectations faced by members of a certain cultural group. These stimuli and expectations are explicitly or implicitly communicated to people through social institutions, their rules and everyday practice, which are, in turn, based on cultural values. For example, a cultural value of modesty and subordination is expressed in the stimuli and expectations that induce the spread of conformity and a desire to "keep in the background." In addition, this does not quite favour the development of entrepreneurship and innovative activity as key development factors. Thus, pressing an individual, the social institutions as culture generators determine the direction of his actions and his entire life activity [Pylypenko, 2017].

Sh. Schwartz based his research on measuring the ten types of individual values (security, conformity, tradition, self-direction, stimulation, hedonism, achievement, power, benevolence, universalism), which reflect motivational directions in terms of person's basic needs. Shalom Schwarz obtained these ten types of values on the base of averaged human value priorities that were revealed by the empirical studies in 48 countries of the world [Schwartz \& Ros, 1995; Schwartz \& Bardy, 1997]. These values were united into larger value categories "Openness to Changes - Conservatism" and "Self-Transcendence — Self-Enhancement", which represent bipolar pairs of competing values. According to Schwartz, it is the conflict or harmony of values that determines the strategy of human behaviour.

The goal of our research was, using the above approaches, to reveal socio-cultural factors of innovative development through a comparison of value dispositions to innovations of various culture representatives and to determine either universal or specific patterns of their behaviour in the innovation sector.

\section{Theoretical and empirical evidence of interrelation of culture and innovations}

The science of economics believes that innovative activity depends directly on the expected profitability from implementation of innovations. In the market economy, where competition determines the efficiency of entrepreneurial activity, innovations become a powerful factor of profit maximisation. In conditions of market saturation with various goods and services, the consumer's demand becomes more and more oriented at more complex and differentiated products. This fact boosts the importance of scientific and technical progress as a main factor of creating innovations. The manufacturer who gets control over this factor can make higher profits owing to temporary monopoly over the use of innovations. In case the innovations are successful and spread, the expenditures on their development are covered with an avalanche-like growth effect. This effect is distributed between the innovative entrepreneur and his competitors who reproduce the innovations to support their competitiveness. In addition, the more opportunities the innovator has to keep up the superprofit, the more incentives exist to develop and implement the innovations. Therefore, companies currently have to keep up the "innovative tone", or tough competition will force them out of the market. Thus, to keep up the entrepreneurial innovative activity, especially important is to provide the quality of the institutional environment innovations are unreal without competition, freedom of entrepreneurship, specification and protection of innovation property rights. As these institutions are based on socio-cultural values that determine the behavioural norms and rules for subjects of economic activity, the influence of culture on the innovative activity is quite important.

The founder of the innovative development theory Jozef Schumpeter showed that production develops on the base of human economic activity, which is governed by traditions, customs, routines that support the enterprise's current technology and reproduction cycle [Shumpeter, 
2007]. With time, creation of new samples of engineering and technology, invention of new organisation forms of production and exchange open up new opportunities in using the resource base, means of production and financing sources. That is why the entrepreneur starts changing the combination of production factors, improves them, and directs them to a new combination that should provide for profit maximisation. Implementation of new things undermines the regular course of the production process, makes it impossible to use old production methods, devaluates outmoded equipment. Thus, it gives rise to "creative destruction" of old production modes and provides for onward movement and economic progress.

Discovering the principles of innovation renewal, Jozef Schumpeter highlights the importance of taking into account the informal institutions — traditional thinking, established and customary behaviour, human dispositions to everything that is familiar and understandable. According to Schumpeter, "all knowledge and habits that were acquired some time ago grow strong in us, like a railway bank in the land" [Shumpeter, 2007]. Therefore, innovations always face the inertance of existing institutions, which is not easy to get over. This is why, the innovation process needs important institutional innovations - creation of new social and economic institutions based on behavioural models that are adequate to new conditions. The key figure in the process of innovative economic renewal is an innovative entrepreneur who breaks the customary development process and goes beyond the known. Therefore, it is his personal characteristics that are an important innovativeness factor. The cross-cultural studies proved that adventurism, strive for searching and mastering of the new and unknown, risk and vigour are the qualities that conform to a greater degree to the market entrepreneurial systems.

At this point, special attention should be paid to the fact that innovations are dual by nature. On the one hand, an innovation is a new feature, which, when penetrating into society, allows one to achieve social and economic benefit. On the other hand, innovations are a result of creative work and inventiveness and they also have the socio-cultural nature. In fact, an entrepreneur is by no means always an inventor. As a rule, he deals with direct implementation of innovations. Innovations are created by other people who are creative and knowledge-driven, who are endowed with a disposition to creative search. The conception of society subsystems developed by the French school institutionalists [Sapir, 2001], proves that innovations motivated by profit maximisation are important in the market subsystem only. In the creative subsystem, they are related to a desire of originality, which is determined by traditions of a certain culture and realised in any activity area - from the fundamental science to art. This means that innovative activity depends directly on socio-cultural values that determine human dispositions, habits and motivations.

Some aspects of this dependency have been proved empirically. Therefore, Scott Shane showed that societies with dominant individualistic values are more inventive and more disposed to innovations [Shane, 1992]. Similar results were obtained by Stephen Dollinger, Philip Burke, Nathaniel Gump [Dollinger et al., 2007], who established a positive correlation between the individualistic values and creativity, and Nadezhda Lebedeva and Alexander Tatarko [Lebedeva \& Tatarko, 2011], who revealed a close relation of self-direction, stimulation and hedonism values with the general innovation index. There arises a question of whether the anti-innovativeness of the Ukrainian economy is stipulated with the peculiarities of our culture. The answer should be apparently sought in the dominant socio-cultural values.

To answer this question, it is necessary to analyse the socio-cultural values in Ukraine and in other world countries that are more successful in their innovative development. For comparison, we have chosen 20 European countries, as well as two largest innovative economies of the world - the USA and Japan. If compared to our country, the indicators of higher economic 
and innovative development of the selected countries are as follows. First, it is the population's higher standard of living. Second, these countries have better performance indicators of their innovative activity, in particular: the position in the world innovative activity rating, the specific weight of innovative enterprises, the share of research and development expenditures within the GDP and the specific weight of export of high-technology goods in the total volume of industrial export (see Table 1).

Table 1. Indicators of innovative activity and living standard in selected world countries

\begin{tabular}{|c|c|c|c|c|c|}
\hline Countries & 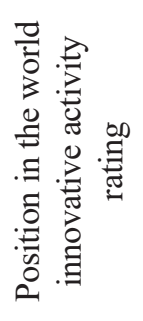 & 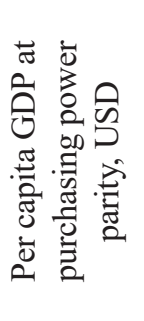 & 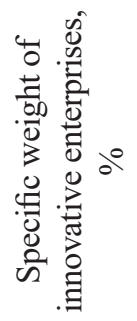 & 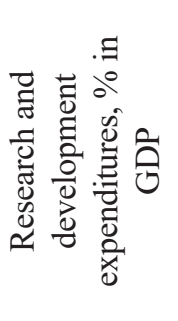 & 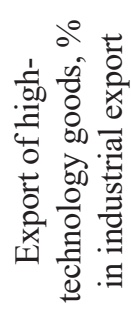 \\
\hline USA & 6 & 59972 & - & 2,85 & 20,0 \\
\hline Japan & 13 & 42942 & 47,9 & 1,3 & 7,5 \\
\hline Austria & 20 & 50031 & 59,5 & 3,1 & 31,69 \\
\hline Belgium & 25 & 46621 & 64,2 & 2,5 & 12,5 \\
\hline United Kingdom & 4 & 44292 & 60,2 & 1,7 & 21,8 \\
\hline Hungary & 33 & 29559 & 25,6 & 1,4 & 14,0 \\
\hline Germany & 9 & 50804 & 67,0 & 2,9 & 16,7 \\
\hline Israel & 11 & 53933 & 49,0 & 4,3 & 18,4 \\
\hline Spain & 28 & 38381 & 36,4 & 1,2 & 7,0 \\
\hline Italy & 31 & 38233 & 48,7 & 1,3 & 7,5 \\
\hline Lithuania & 40 & 32379 & 43,3 & 1,0 & 11,7 \\
\hline Netherlands & 2 & 53933 & 55,3 & 2,0 & 17,8 \\
\hline Norway & 19 & 72058 & 57,6 & 1,9 & 19,3 \\
\hline Poland & 39 & 29642 & 21,0 & 1,0 & 8,5 \\
\hline Russia & 46 & 27893 & 9,7 & 1,1 & 10,7 \\
\hline Slovenia & 30 & 23654 & 45,9 & 2,2 & 7,4 \\
\hline Ukraine & 43 & 8754 & 16,2 & 0,62 & 7,3 \\
\hline Finland & 7 & 44492 & 55,3 & 2,9 & 8,4 \\
\hline France & 16 & 44081 & 56,4 & 2,2 & 26,7 \\
\hline Czech Republic & 27 & 35537 & 42,0 & 1,9 & 13,9 \\
\hline Switzerland & 1 & 62125 & 75,3 & 3,0 & 27,1 \\
\hline Sweden & 3 & 51185 & 54,2 & 3,3 & 14,3 \\
\hline Estonia & 24 & 31649 & 26,5 & 1,5 & 10,3 \\
\hline
\end{tabular}

Based on: [The Global Innovation Index, 2018; World Data Atlas, 2018; Indicators of innovative activity, 2017]. 
To verify empirically the hypothesis on the dependence of innovative activity on socio-cultural values, we have used the data obtained in the framework of the long-term comparison project - the "European Social Survey" (ESS), which was based on Schwartz's methods [Schwartz, 2011]. The publicly available research results and a vast array of data on 36 European countries allows us to determine the general features and reveal specific characteristics of value orientations of average Ukrainians and citizens of other countries in terms of their influence on person's innovative dispositions.

Table 2 demonstrates the generalised value categories "Openness to Changes Conservatism" and "Self-Transcendence - Self-Enhancement", which unite such value orientations as security, conformity, tradition, self-direction, stimulation, hedonism, achievement, power, benevolence and universalism.

Table 2. Sh. Schwartz's classification of value orientations

\begin{tabular}{|c|c|c|c|}
\hline $\begin{array}{l}\text { Integral } \\
\text { axis }\end{array}$ & $\begin{array}{c}\text { Value } \\
\text { category }\end{array}$ & $\begin{array}{c}\text { Value } \\
\text { orientations }\end{array}$ & Values \\
\hline \multirow{6}{*}{ 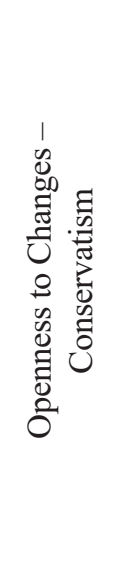 } & \multirow{3}{*}{ Conservatism } & Security & Family security, national security, social order \\
\hline & & Tradition & $\begin{array}{l}\text { Acceptance and respect of traditions and ideas } \\
\text { that one's culture or religion provides }\end{array}$ \\
\hline & & Conformity & $\begin{array}{l}\text { Avoiding of actions that are likely to upset or } \\
\text { harm others or violate social norms }\end{array}$ \\
\hline & \multirow{3}{*}{$\begin{array}{l}\text { Openness to } \\
\text { Changes }\end{array}$} & Self-Direction & $\begin{array}{l}\text { Independent thought and action-choosing, cre- } \\
\text { ativity, freedom, cognition }\end{array}$ \\
\hline & & Stimulation & Life full of excitement, novelty and challenges \\
\hline & & Hedonism & Sensuous gratification, enjoying life, comfort \\
\hline \multirow{4}{*}{ 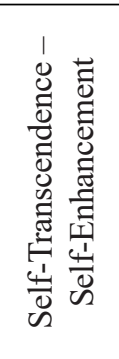 } & \multirow{2}{*}{$\begin{array}{l}\text { Self- } \\
\text { Transcendence }\end{array}$} & Benevolence & $\begin{array}{l}\text { Preserving and enhancing the welfare of the close } \\
\text { circle people }\end{array}$ \\
\hline & & Universalism & $\begin{array}{l}\text { Wisdom, justice, equality, peace, beauty, toler- } \\
\text { ance, unity with nature, environment protection }\end{array}$ \\
\hline & \multirow{2}{*}{$\begin{array}{l}\text { Self- } \\
\text { Enhancement }\end{array}$} & Power & $\begin{array}{l}\text { Prestige, wealth, control over people and resourc- } \\
\text { es, social status, authority }\end{array}$ \\
\hline & & Achievement & $\begin{array}{l}\text { Personal success and its demonstration, ambition, } \\
\text { competence }\end{array}$ \\
\hline
\end{tabular}

Source, compiled according to: [Schwartz \& Bilsky, 1990].

The value category "Openness to Changes - Conservatism" describes the conflict between values that emphasize independence of thought, action, and feelings and readiness for change (self-direction, stimulation) and values that emphasize order, self-restriction, preservation of the past, and resistance to change (security, conformity, tradition). The value category "Self-Transcendence - Self-Enhancement" reflects the conflict between values that emphasize concern for the welfare in the interests of others (universalism, benevolence) 
and values that emphasize pursuit of one's own interests, relative success and dominance over others (power, achievement). Hedonism shares elements of both "openness to change" and "self-enhancement", but it is still closer to the openness to change [Schwartz, 2012].

The authors of this article have used the open access empirical data of the European survey at the official website of the European Social Survey [European Social Survey, 2018]. We focused on the eighth round data (2016) for European countries and the sixth round data (2012) for Ukraine, which joined the project only in 2004 and left the project in 2012 due to the military and political events in the country. When studying the dynamics of value orientations, Shalom Schwartz came to a conclusion that they change rather slowly (36 samples in 21 countries of the world during seven years, taking into account the socioeconomic and political shocks). Hence, the time span of four years between the indicators for Europe and Ukraine can be considered inessential.

We have estimated the value orientations by four value categories of population in 21 European countries in conformity with Sh. Schwartz's methods presented at the official website of the European Social Survey [European Social Survey, 2018]. The indices themselves were calculated as centred indicators and thus demonstrate the degree of priority of a certain value in a respondent's intraindividual value hierarchy. Negative indices testify to the fact that the significance of this value is lower than the total average significance peculiar to this individual. On the contrary, positive indices indicate that the significance of this value is higher than average. The lower the index is, the more significant this value is for a respondent in relation to his average significance of all the Schwartz's values. Table 3 presents the value orientation indices for 21 selected European countries that were sampled for our analysis of innovative activity and living standard achieved in these countries.

\section{Table 3. Schwartz's value orientation indices by four population categories in 21 European countries}

\begin{tabular}{|l|c|c|c|c|}
\hline & Conservatism & $\begin{array}{c}\text { Openness to } \\
\text { Changes }\end{array}$ & Self-Enhancement & Self-Transcendence \\
\hline Austria & $-0,0568$ & 0,1771 & 0,4553 & $-0,5298$ \\
\hline Belgium & $-0,0212$ & 0,0738 & 0,7209 & $-0,6634$ \\
\hline $\begin{array}{l}\text { United King- } \\
\text { dom }\end{array}$ & $-0,014$ & 0,1139 & 0,7415 & $-0,7394$ \\
\hline Hungary & $-0,0215$ & 0,0785 & 0,275 & $-0,3081$ \\
\hline Germany & 0,0467 & 0,0448 & 0,8917 & $-0,8496$ \\
\hline Israel & $-0,0556$ & 0,1941 & 0,2228 & $-0,3681$ \\
\hline Spain & $-0,2464$ & 0,2234 & 1,1368 & $-0,8776$ \\
\hline Italy & $-0,3383$ & 0,5249 & 0,2664 & $-0,43$ \\
\hline Lithuania & $-0,2083$ & 0,3147 & 0,0483 & $-0,1532$ \\
\hline Netherlands & 0,1642 & $-0,1174$ & 0,7595 & $-0,6834$ \\
\hline Norway & $-0,0493$ & 0,0803 & 0,8362 & $-0,7487$ \\
\hline Poland & $-0,3533$ & 0,4802 & 0,5324 & $-0,5784$ \\
\hline Russia & $-0,1879$ & 0,322 & 0,2164 & $-0,3241$ \\
\hline Slovenia & $-0,1557$ & 0,1275 & 0,6259 & $-0,4609$ \\
\hline
\end{tabular}




\begin{tabular}{|c|c|c|c|c|}
\hline Ukraine & $-0,2031$ & 0,408 & 0,1818 & $-0,377$ \\
\hline Finland & $-0,0203$ & $-0,0408$ & 1,1654 & $-0,8732$ \\
\hline \begin{tabular}{|l|} 
France \\
\end{tabular} & $-0,0378$ & $-0,0381$ & 1,1291 & $-0,8223$ \\
\hline $\begin{array}{l}\text { Czech } \\
\text { Republic }\end{array}$ & $-0,1465$ & 0,1485 & 0,2898 & $-0,2398$ \\
\hline Switzerland & 0,1342 & $-0,0188$ & 0,7171 & $-0,7256$ \\
\hline \begin{tabular}{|l|} 
Sweden \\
\end{tabular} & 0,1787 & $-0,0752$ & 0,9466 & $-0,8924$ \\
\hline Estonia & $-0,1398$ & 0,1456 & 0,8117 & $-0,6693$ \\
\hline
\end{tabular}

Based on: [The European Social Survey 2018].

The comparison of value indices by the category "Openness to Changes - Conservatism" in the group of investigated countries allows us to state that Ukrainians tend towards a more pronounced "Conservatism" value indicator $(-0,2031)$ if compared to the "Openness to Changes" indicator $(0,408)$. This fact means that our society's culture does not encourage inventiveness and innovativeness, as people have feebly-marked needs for independent thought, creativity, freedom of cognition, as well as the needs for life activity full of excitement, challenges and commitment to win. In addition, we appeared to be strongly oriented to preserving the stability and order that are based on acceptance and respect of traditions and ideas that one's culture or religion provides.

As the diagram in Fig.1 shows, upon the "Conservatism" value indicator, Ukraine's population ranks $17^{\text {th }}$ and neighbours Russia $(-0,1879)$, leaving behind only Lithuania ($0,2083)$, Spain $(-0,2464)$, Italy $(-0,3383)$ and Poland $(-0,3533)$.

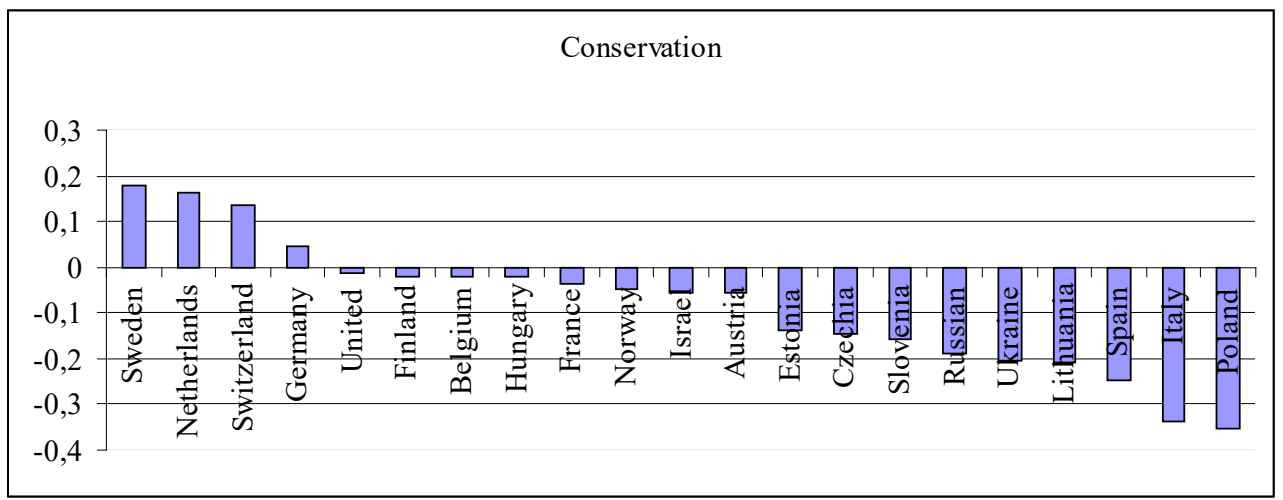

Fig.1. Average "Conservatism” Index

As relating to the "Openness to Changes" value indicator (Fig. 2), Ukrainians are very far from such "creative" European countries as the Netherlands $(-0,1174)$, Sweden $(-0,0752)$, Finland $(-0,0203)$, France $(-0,0378)$ and Switzerland $(-0,0188)$. Our position in this value orientation is the same close to Italy $(0,5249)$, Poland $(0,4802)$, Lithuania $(0,3147)$, Spain $(0,2234)$ and Russia $(0,322)$. 


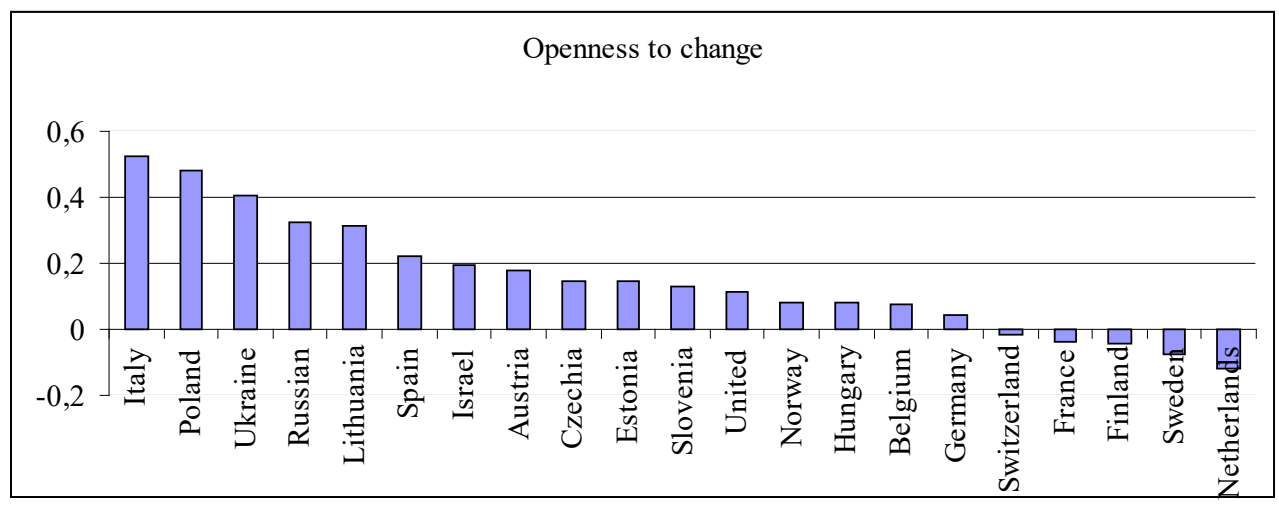

Fig.2. Average "Openness to Changes" Index.

Even after the roughest comparison with the data of Table 1, it is easy to note that it is these countries that also hold rather weak positions in the international innovative activity rating: Italy $-31^{\text {st }}$ position, Poland $-39^{\text {th }}$ position, Lithuania $-40^{\text {th }}$ position, Spain $-28^{\text {th }}$ position, Russia $-46^{\text {th }}$ position, even if they have higher GDP per capital than Ukraine. It appears that value orientations of people that underlie their motivational behaviour types, do not encourage innovativeness itself. However, this does not mean that the innovative development type is impossible in the countries whose population, in terms of values, is not disposed to innovations. The only point is that in such cultural environment it is not enough to have just market incentives to innovations. Therefore, fixation on the market as innovation producing mechanism (J.Shumpeter's model) cannot be a priority of Ukraine's economic policy. Nevertheless, the government is empowered with an opportunity to form, through the institutional reforms, an innovation environment adequate to the existing socio-cultural values.

In this regard, it should be noted that the rate of flow of institutional changes strongly depends on formal and informal restrictions that are built in the language, material things and convictions and determine the forms of interpersonal interaction. As Douglass North notes, "The dominant beliefs, that is, of those economic and political entrepreneurs in a position to make policies, over time result in the accretion of a structure of institutions that determine economic and political behaviour. The resultant institutional matrix imposes severe constraints on the choice opportunities for leaders who try to modify the existing institutions or to create new ones in order to improve their economic and political positions. The path dependence that results typically makes change incremental. A key to understanding the process of changes is the intentionality of the players standing behind the process of institutional changes" [North, 2005]. Thus, it is important to figure out the orientation of people's consciousness to the values that determine the possibility of change itself.

On the diagrams illustrating the countries' positions by value indices of the "SelfTranscendence - Self-Enhancement" category (Fig. 3 and 4), we find out that Ukraine is rather highly oriented at self-determination values (Self-transcendence) $(-0,377)$ to the disadvantage of self-assertion values (Self-enhancement) $(0,1818)$. 


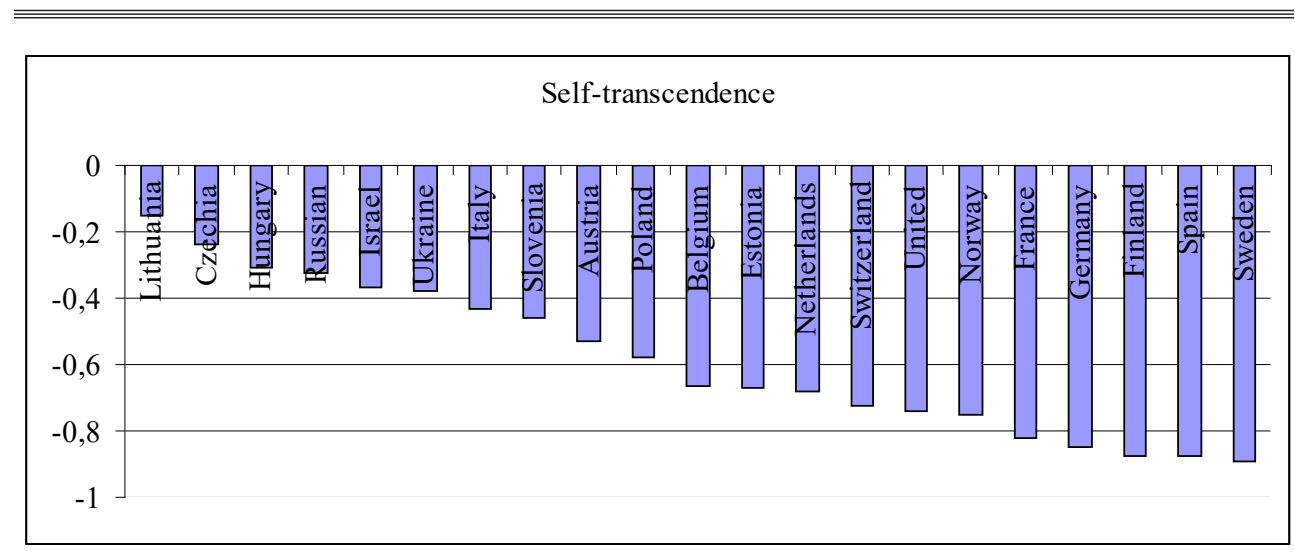

Fig. 3. Average "Self-Transcendence" Index

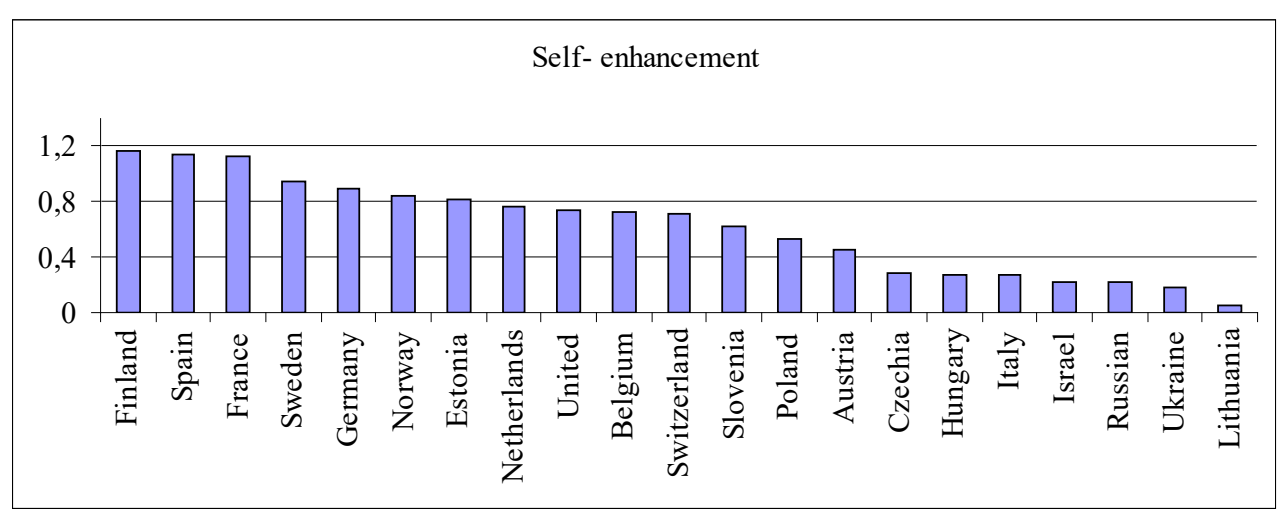

Fig. 4. Average "Self-Enhancement" Index

This testifies to the Ukrainians' great disposition to achieve personal success due to their pursuance of positive interaction for the welfare of the group (value orientations "Benevolence" and "Universalism"). Though, if to compare Ukraine with more innovatively successful Sweden, Switzerland, the Netherlands, the United kingdom, Finland and Germany (that are top ten countries upon the international innovative activity rating), the "SelfEnhancement" index in the Ukrainian society is much lower. In other words, we are disposed to accept and produce changes, but we do this more slowly than the innovatively developed countries.

A more vivid picture of relative inertance of Ukraine's institutional reforms is given in the analysis of countries' positions according to the "Self-Enhancement" value indices. As Fig. 4 shows, upon this value orientation we are at a great distance from the above countries, ranking second among the 21 European countries upon the "Achievement" and "Power" value orientations that reflect a strive for bigging up the social status and influence on other people. Our closest neighbours in this value orientation segment are exactly the countries with not high or average innovative activity — Latvia, Russia, Italy, Hungary, Czech Republic and Israel. 
As we can see, the domination of "Self-Enhancement" value orientations is not favourable for the innovative development of Ukraine, as it hampers the institutional reforms. As it is commonly known, any institute changes eventually lead to redistribution of power. It means that a power oriented society will resist changes. Therefore, in relation to Ukraine, we can note the people's dominant value disposition to making changes, which is, however, somewhat burdened with greater orientation to power, if compared to other European countries.

\section{Conclusions}

If to proceed from a premise that a society is a complex system, with various human life activity areas that interact and influence each other, one can present innovations as a technical and economic phenomenon and, at the same time, as a product of a certain culture. Culture and innovations are interrelated in value determination of innovative or anti-innovative types of human activity motivation, what makes people of different countries either more disposed to creativity, inventiveness, innovativeness and changes or makes them more conservative.

The results of investigating the value basis of innovative activity according to the ESS data have proved the theoretical hypothesis of a close relation of culture and innovations: the countries with dominant "Openness to changes" values had more developed inventiveness and innovativeness than others. And, vice versa, with dominant traditionality and conformity ("Conservatism" values), innovativeness was low. In turn, significant were the "Selftranscendence" values, as they facilitate the formation of an environment favourable for institutional innovations.

The population of Ukraine is distinguished with a more pronounced orientation to the values of security, traditionality and conformity ("Conservatism") to the disadvantage of "Openness to changes" values. It is also characterized with higher orientation to selfdetermination values ("Self-transcendence"), with more pronounced self-assertion values ("Self-enhancement"), if compared to other European countries. It means that an average Ukrainian is extremely careful and conservative in his actions. His psychological portrait does not have dominant needs for novelty, creativity and freedom. He does not have a pronounced disposition to changes and risk. That is why we cannot stake on individual innovativeness only as a factor of social welfare growth, as culture does not encourage creativity as a base for person's innovative pursuits. With this in view, we do not evidently have a critical mass of people empowered with the features of a Shumpeterian innovative entrepreneur.

However, this does not mean that Ukraine cannot clear the cultural barrier on its way to the innovative development type. First, the existing system of values is largely a heritage of centrally planned economy and the cultivated value orientations. Therefore, assuming that the formation of society's dominant value orientations is a result of rather long historical periods of time (that are at least equal to the life of several generations), the twenty plus years of market transformations is not enough for a cardinal change in value orientations of the majority of Ukraine's population. Moreover, the character and rate of value changes have become the result of low performance of market transformations in Ukraine as well. In our country, real reforms were often substituted for their imitation. The social and economic policy of a large number of governments in power was inconsistent and half-measured. The state authorities system proved to be most highly corrupted. All these factors shook the average Ukrainian's faith in market reforms and affected his value perception and world outlook.

Second, as the world record shows, many countries whose systems of people's value orientations did not facilitate the innovative development, succeeded in clearing this 
contradiction due to the government's relevant economic policy. A vivid example is Japan. Being highly conformal and traditional, the Japanese nevertheless reached rather high indices of social welfare and innovative economic development, ranking $13^{\text {th }}$ in the world innovative economies rating (see Table 1). This was largely due to the government's stimulating policy aimed at the creation of an efficient system of development motivational mechanisms. Understanding its nation's mind, in 1960s-1970s, the Japanese government did not stake on creation of new technologies - it staked on their imitation. The preferential treatment in fiscal and credit and financial spheres for the purpose of large import of western advanced technologies and control methods, on the one hand, and gradual stimulation of production and export of domestic high technology products (first of all, electronics), on the other hand, resulted in Japan's turning into one of the most developed market economies of the world in a rather short historical period. Similarly developing were South Korea and Taiwan that, within a relatively short time, made the way from developing to developed innovative countries.

Of course, Ukraine cannot purely repeat the experience of the economic wonder of the "East Asian tigers". This is also due to its inability of pursuing an aggressive protectionist policy in the world technology markets. We must understand that the mankind of today has entered an epoch of cardinal changes marked by a shift from the industrial civilisation to a post-industrial, integral and humanistically noospheric civilisation. Such conditions, which are largely determined by achievements of modern information revolution and globalisation processes, swiftly increase the interdependence of national economies and form a single economic, technological, financial, education, information and humanitarian space. Human resources and technologies are faster and faster travelling in the world. This facilitates a more rapid approaching of cultures, certain unification of values, with preserving the cultural diversity and mentality features of various nations. Due to this, national states have fewer and fewer levers of influence on innovative development, staking on the domestic policy potential only. We currently need a different approach to the formation of a longterm innovation strategy, an approach that would account for global tendencies of social and economic development. For Ukraine, this approach means a deeper integration in the world science and technology space as an equal partner, searching for its niche in a constantly developing world segment of creative and innovative activity, with cultural diversity being a powerful source of development.

\section{미 References}

Dollinger, Stephen, Philip Burke, and Nathaniel Gump. Creativity and Values. Creativity Research Journal, 19 (2-3), 2007: 91 - 103.

Indicators of innovative activity, 2017: statistical compilation, available at: https://issek.hse. $\mathrm{ru} /$ data/2017/03/15/1170155477/Innovations\%202017.pdf (application December 11, 2018).

Lebedeva, Nadezhda and Alexander Tatarko. Culture as a factor of social progress. Moscow: 2009.

Lebedeva, Nadezhda and Alexander Tatarko. Culture and Economic Behaviours. Moscow: 2011.

North, Douglass. Understanding the Process of Economic Change. Prinston University Press: 2005.

Pylypenko, Yurii. The technological system of society and its structure. Scientific Bulletin of the NMU, 6 (132), 2012: 147-153.

Pylypenko, Hanna. Socio-cultural factors of economic development. Dnipro: 2017. 
Research and development in 2018. Science, technology and innovation. Economic statistics, available at: http://www.ukrstat.gov.ua (application March 17, 2019).

Sapir, Jac. Towards an economic theory of inhomogeneous systems. Moscow: 2001.

Shane, Scott. Why do some societies invent more than others. Journal of Business Venturing. 7, 1992: $29-46$.

Schwartz, Shalom, and Wolfgang Bilsky. Towards a theory of the universal structure and content of values: Extensions and cross-cultural replications. Journal of Personality and Social Psychology, 58, 1990: 878 - 891.

Schwartz, Shalom, and Mark Ros. Values in the West: A theoretical and empirical challenge to the Individualism-Collectivism cultural dimension. World Psychology, 1, 1995: 99 -122 .

Schwartz, Shalom, Bardy, Aurtur. Influence of adaptation to communist rule on value priorities in Eastern Europe. Political Psychology, 18, 1997: 385 - 410.

Schwartz, Shalom. Values: Individual and cultural. Cambridge: 2011.

Schwartz, Shalom. An Overview of the Schwartz Theory of Basic Values. Online Readings in Psychology and Culture, 2 (1), 2012: $1-20$.

Shumpeter, Jozef. The Theory of Economic Development. Capitalism, socialism and democracy. Moscow: 2007.

The Global Innovation Index 2018, INSEAD, WIPO, Cornell University: 2019. Available at: https://www.wipo.int/edocs/pubdocs/en/wipo_pub_gii_2018.pdf (application Mach 18, 2019).

The European Social Survey 2018, European Social Research website, available at: https:// www.europeansocialsurvey.org/.- Title from the screen (application December 13, 2018).

Yakovets, Yurii. Rent, Anti-Rent, Quasi-Rent in Global Civilization Dimension. Moscow: 2003.

World Data Atlas. World and regional statistics, national data, maps and ratings. Available at: https://knoema.ru/atlas (application December 10, 2018). 